\title{
The development of anterior-posterior spinal curvature in children aged 7-12 years
}

\author{
Justyna Drzał-Grabiec ${ }^{1}$, Sławomir Snela ${ }^{1,2}$, Aleksandra Truszczyńska ${ }^{3}$ \\ 1 Institute of Physiotherapy, University of Rzeszów, Rzeszów, Poland; ${ }^{2}$ Department of Paediatric Orthopaedics and \\ Traumatology, Regional Hospital No 2, Rzeszów, Poland; ${ }^{3}$ Faculty of Rehabilitation, Józef Piłsudski University of Physical \\ Education, Warsaw, Poland
}

\section{Summary}

Study aim: Body posture changes depend on numerous factors. The purpose of this study was to assess the changes in posture in the sagittal plane of children aged $7-12$ years.

Material and methods: Postural changes were determined by assessing the postural parameters in the sagittal plane. The measurements were recorded in children attending selected primary schools. In total, 562 subjects were included in the study, including 278 boys and 284 girls. The body posture was assessed photogrammetrically based on the moiré effect, whereby 5 postural parameters were integrated within the measurement methodology.

Results: The results indicated a naturalistic tendency in postural development - the postural parameters changed with age in a dynamic fashion; and the postural measurements for boys and girls differed in terms of their range.

Conclusions: The study findings can be used for the accurate mapping of normal postural development and, inter alia, for the detection and diagnosis of an emerging abnormal posture. Importantly, a correct postural assessment algorithm for children should include the subject's age and sex.

\section{Keywords: Body defect - Body posture - Children - Photogrammetric method}

\section{Introduction}

Posture refers to the relative position of the human body and its orientation in space. Posture also involves the muscle activation that leads to postural adjustments. Such adjustments are controlled by the central nervous system [2]. The analysis of the human spine morphology, especially in children and adolescents, can be challenging due to the complex interactions occurring between the anatomical, muscular and psychological factors [7]. To prevent spinal deformities and postural asymmetries from developing, an early and objective diagnosis of postural changes is essential $[4,5]$. To date, the gold standard for the detection of pathological changes in the spinal morphology (e.g. scoliosis) includes clinical examinations alongside radiological techniques such as X-rays, computer tomographies and MRI $[4,9,10]$.

The prepuberal phase and puberty are the periods of life during which the posture undergoes many adjustments and adaptations due to changes occurring in the child's body and to demanding psychosocial factors. Between 7 and 12 years of age, a child's posture undergoes a big transformation in order to reach a compatible balance with the new corporal proportions [16]. Bankoff and Brighetti discuss the question of the formation of the body schema in childhood through the motor experiences occurring during this period, and how an imbalance in the tonic-postural structure can last for an individual's entire adolescence and adult life [1].

High incidences of postural alterations occur in children of school age. Some of these reflect a normal postural development, and will be corrected during the child's growth. On the other hand, some alterations are asymmetries that can be caused by the daily demands on the body and can result in a negative impact on the quality of life during both childhood and adulthood [16].

The purpose of the study was to present the dynamics of anterior-posterior spinal curvature development in children aged 7-12. In addition, a gender-specific systematic comparison was made of the selected postural parameters within the sagittal plane. The following research questions 
were stated: Does spinal curvature depend on age in this adolescent group? And are there significant differences regarding gender?

\section{Materials and methods}

In total, 562 subjects were enrolled in the study, including 278 boys (49.38\%) and 284 girls (50.62\%) with a mean age $9.67 \pm 1.7$, body weight $32.33 \pm 6.6 \mathrm{~kg}$ and body height $138 \pm 10.3 \mathrm{~cm}$. In all cases, the parents/guardians were required to provide a written informed consent prior to the inclusion of a subject within the study.

Inclusion criteria: Healthy children who perform regular daily activities and participate in sport only in physical education class.

Exclusion criteria: Obesity, orthopaedic (feet, knee, hips or spine) malformations or injuries, neurological disorders, and participation in any professional sport training.

The demographic distribution of the cohort group was as follows: 7 year olds -83 children $(14.77 \%)$; 8 year olds -77 children $(13.70 \%)$; 9 year olds -100 children $(17.79 \%)$; 10 year olds -86 children $(15.30 \%)$, which represented the smallest subgroup; 11 year olds 112 children $(19.93 \%)$, which constituted the largest proportional representation of the cohort population; and 12 year old children - 104 subjects (constituting $18.51 \%$ of the study group population). The subjects were classified into the respective age groups based on the following principle: e.g. children whose calendar age at the time of testing was between 6.5-7.5 years were classified as belonging to the 7 year old age subgroup. The distribution regarding gender in every age group is presented in Table 1.

The consent of the Ethical Board at the University of Rzeszów was obtained prior to undertaking the current study. According to the assumptions and purpose of the research, the exclusion criteria included the following: age of less than 7 or more than 12 years; a lack of written informed consent; an incomplete medical history or associated documentation; and a history of locomotor abnormalities.

\section{Measurement system}

In each individual subject, 56 postural measurements were recorded using the photogrammetric method based on the moiré effect. All of the measurements were conducted according to commonly accepted principles and guidelines [17]. The moiré method is based on the principle of light beam refraction between the grid screen and its generated shadow, which is projected onto the patient who is positioned behind the screen. Light interference occurs following the propagation of light waves through the raster. As a result, a contour graph, commonly referred to as a moiré pattern, is obtained (Fig.1). The shape of the topographic lines of the graph depend on the shape of the projected area (usually the patient's back), and the distance between the grid screen and the patient. The height of each contour line can then be determined by assessing the distance between the light source, the patient and the recording camera. The moiré method allows for the generation of a three-dimensional image of the subject's back. This generated image can be used for the calculation and analysis of 93 postural parameters. Such a methodology is non-invasive in its nature and offers a relatively efficient and accurate option for assessing the body posture in three dimensions. In addition, the computer-aided technique allows for the storage and analysis of large volumes of recorded data. This method is widely used in many countries for the assessment, gauging treatment procedures and analysing the progression of scoliosis in children [15]. Importantly, the method does not replace the currently used x-ray imaging techniques, but has been reported as an invaluable screening tool.

\section{Test operating procedure}

Initially, specific anthropometric points were marked on the subject's back. Such points included the scapular lower angles, the spinous processes and the posterior superior iliac spines. The patient's related demographic and medical data was entered into a centralised database. In

Table 1. Sex distribution in age groups

\begin{tabular}{lccc}
\hline & Age & number & $\%$ \\
\hline Girls & 7 & 32 & 38.6 \\
Boys & 51 & 61.4 \\
Sum & & 83 & 0.0 \\
\hline Girls & 8 & 42 & 54.5 \\
Boys & & 35 & 45.5 \\
Sum & & 77 & 0.0 \\
\hline Girls & 9 & 53 & 53.0 \\
Boys & & 47 & 47.0 \\
Sum & & 100 & 0.0 \\
\hline Girls & 10 & 44 & 51.2 \\
Boys & & 42 & 48.8 \\
Sum & & 86 & 0.0 \\
\hline Girls & 11 & 54 & 48.2 \\
Boys & & 58 & 51.8 \\
Sum & & 112 & 0.0 \\
\hline Girls & 12 & 59 & 56.7 \\
Boys & & 45 & 43.3 \\
Sum & & 104 & 0.0 \\
\hline
\end{tabular}


addition, other data relating to the study subject was recorded. This included information relating to the following: the knees and heels; thorax; history of trauma, surgery and locomotor abnormalities; as well as the gait observed during clinical observations.

The patient was then positioned at the appropriate distance with the subject's back towards the camera. The lights in the room were then switched off. The alignment of the patient was corrected as necessary, in order to ensure that the pelvic rotation angle was 0 degrees. The generated digital image of the back was then recorded and saved within a designated centralised database. From the series of images that were generated, an optimal image was selected which correlated with the minimal pelvic rotation and corresponded with the modal patient's posture.

Following the image selection and recording, the examiner marked the necessary anthropometric points using specially designated software. A 3-D image was then generated. Based on the generated photograms, it was possible to determine several dozen postural parameters. For the purposes of the current research study, 5 parameters were assessed (see Section 2.4). Fig. 1 presents the method for the determination of the 5 parameters.

Five parameters were included in the analysis, namely: Alpha $(\alpha)$ angle - the inclination of the lumbosacral vertebral segment; Beta $(\beta)$ angle - the inclination of the thoracolumbar vertebral segment; Gamma $(\gamma)$ angle the inclination of the upper thoracic vertebral segment; the angle of thoracic kyphosis (ATK); and the angle of lumbar lordosis (ALL). The angle of thoracic kyphosis was calculated according to the following equation: ATK $=180-(\beta-\gamma)$; whereas the ALL was calculated as follows: $\mathrm{ALL}=180-(\alpha+\beta)$.

\section{Statistical analysis}

The parameters were compared between the different subgroups. In order to compare the parameters between the two gender groups, the non-parametric Mann-Whitney $\mathrm{U}$ test for independent variables was used. In order to compare the parameters between the age subgroups, the non-parametric multiple comparison Kruskal-Wallis test for independent variables was used. In all cases, a p-value $<0.05$ indicated a statistical significance.

To verify the normality of distribution, the W ShapiroWilka test was used.

\section{Results}

Five postural parameters characterising the shape of the anterior-posterior curvatures were analysed. In Tables 2-6, the spinal angles divided by the subjects' age are presented.

Significantly significant differences were noted between boys and girls in the 7 year old and 9 year old groups. The girls had a higher Alpha angle and their lordosis was bigger (Table 2). The Beta angle was significantly different between boys and girls only in the 10 year old group of children i.e. among the boys it was higher (Table 3). There were no differences in the Gamma angle between the sexes until the age of 10 , where significant differences were noted (in all of the age groups from 10-12), with the boys having a significantly greater Gamma angle (Table 4). The angle of thoracic kyphosis was significantly greater among the girls in 9, 10 and 12 age groups (Table 5). Similar differences were noted for the lumbar lordosis angle, where there were no differences until the age of 11, after which a significantly greater angle was found among the boys (Table 6).

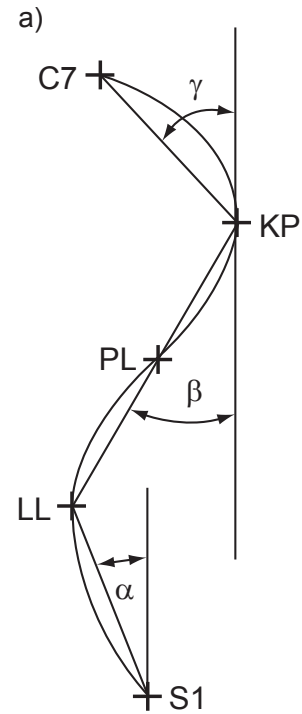

b)

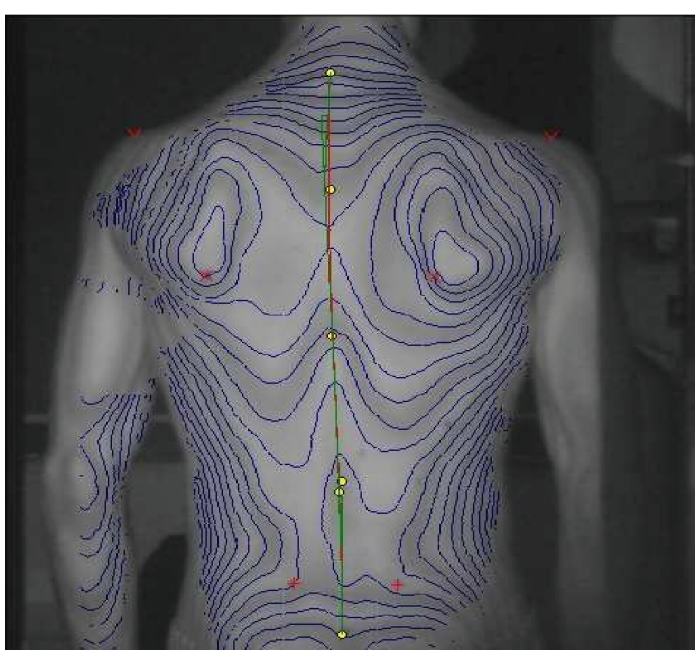

Fig. 1. Tested parameters and their derivation (a), and a generated contour map of the back (b) 
Table 2. Alfa angle with regard to age and sex

\begin{tabular}{|c|c|c|c|c|c|c|c|}
\hline & Age & Sex & Mean $\pm \mathrm{SD}$ & Mediana & Minimum & Maximum & $\mathrm{p}$ \\
\hline \multirow{12}{*}{ Alfa angle [deg] } & \multirow{2}{*}{7} & Girls & $9.51 \pm 3.89$ & 8.50 & 3.20 & 18.70 & \multirow{2}{*}{0.03} \\
\hline & & Boys & $7.36 \pm 4.18$ & 6.90 & -0.70 & 17.60 & \\
\hline & \multirow{2}{*}{8} & Girls & $11.26 \pm 4.27$ & 11.35 & -3.10 & 21.10 & \multirow{2}{*}{0.19} \\
\hline & & Boys & $9.84 \pm 4.74$ & 10.40 & -1.00 & 20.70 & \\
\hline & \multirow{2}{*}{9} & Girls & $12.34 \pm 5.21$ & 12.40 & 0.50 & 23.50 & \multirow{2}{*}{0.003} \\
\hline & & Boys & $9.82 \pm 3.42$ & 9.40 & 3.70 & 17.20 & \\
\hline & \multirow{2}{*}{10} & Girls & $16.14 \pm 3.56$ & 16.00 & 10.00 & 23.00 & \multirow{2}{*}{0.33} \\
\hline & & Boys & $15.33 \pm 4.11$ & 15.00 & 7.00 & 23.00 & \\
\hline & \multirow{2}{*}{11} & Girls & $16.74 \pm 3.66$ & 16.00 & 11.00 & 25.00 & \multirow{2}{*}{0.61} \\
\hline & & Boys & $16.08 \pm 3.93$ & 16.00 & 8.00 & 25.00 & \\
\hline & \multirow{2}{*}{12} & Girls & $16.73 \pm 4.11$ & 16.00 & 9.00 & 25.00 & \multirow{2}{*}{0.07} \\
\hline & & Boys & $15.15 \pm 3.94$ & 15.00 & 5.00 & 27.00 & \\
\hline
\end{tabular}

Table 3. Beta angle with regard to age and sex

\begin{tabular}{|c|c|c|c|c|c|c|c|}
\hline & Age & Sex & Mean $\pm \mathrm{SD}$ & Mediana & Minimum & Maximum & $\mathrm{p}$ \\
\hline \multirow{12}{*}{ Beta angle [deg] } & \multirow{2}{*}{7} & Girls & $9.89 \pm 10.15$ & 2.40 & 16.80 & 3.367 & \multirow{2}{*}{0.15} \\
\hline & & Boys & $10.54 \pm 10.00$ & -0.90 & 21.10 & 4.32 & \\
\hline & \multirow{2}{*}{8} & Girls & $9.24 \pm 8.80$ & 1.00 & 25.10 & 4.53 & \multirow{2}{*}{0.65} \\
\hline & & Boys & $9.31 \pm 9.60$ & 2.90 & 15.10 & 3.46 & \\
\hline & \multirow{2}{*}{9} & Girls & $8.04 \pm 8.10$ & 0.60 & 16.30 & 3.66 & \multirow{2}{*}{0.61} \\
\hline & & Boys & $9.72 \pm 9.60$ & 2.10 & 19.10 & 3.89 & \\
\hline & \multirow{2}{*}{10} & Girls & $7.50 \pm 7.50$ & -3.00 & 13.00 & 3.59 & \multirow{2}{*}{0.04} \\
\hline & & Boys & $9.14 \pm 7.00$ & 2.00 & 18.00 & 3.73 & \\
\hline & \multirow{2}{*}{11} & Girls & $8.41 \pm 8.50$ & 1.00 & 15.00 & 3.04 & \multirow{2}{*}{0.16} \\
\hline & & Boys & $7.84 \pm 7.00$ & 0.00 & 19.00 & 3.34 & \\
\hline & \multirow{2}{*}{12} & Girls & $8.02 \pm 7.00$ & 2.00 & 15.00 & 3.34 & \multirow{2}{*}{0.64} \\
\hline & & Boys & $7.53 \pm 8.00$ & -1.00 & 15.00 & 3.43 & \\
\hline
\end{tabular}

Table 4. Gamma angle with regard to age and sex

\begin{tabular}{|c|c|c|c|c|c|c|c|}
\hline & Age & Sex & Mean \pm SD & Mediana & Minimum & Maximum & $\mathrm{p}$ \\
\hline \multirow{12}{*}{ Gama angle [deg] } & \multirow{2}{*}{7} & Girls & $10.86 \pm 10.95$ & 2.90 & 18.50 & 3.78 & \multirow{2}{*}{0.70} \\
\hline & & Boys & $10.98 \pm 11.60$ & 2.30 & 19.00 & 3.53 & \\
\hline & \multirow{2}{*}{8} & Girls & $10.85 \pm 10.85$ & 2.30 & 19.20 & 3.59 & \multirow{2}{*}{0.12} \\
\hline & & Boys & $12.39 \pm 12.30$ & 5.40 & 20.00 & 4.08 & \\
\hline & \multirow{2}{*}{9} & Girls & $12.26 \pm 12.30$ & 4.50 & 22.30 & 3.58 & \multirow{2}{*}{0.57} \\
\hline & & Boys & $12.64 \pm 12.40$ & 2.20 & 19.00 & 4.22 & \\
\hline & \multirow{2}{*}{10} & Girls & $12.27 \pm 12.00$ & 4.00 & 21.00 & 3.34 & \multirow{2}{*}{$<0.001$} \\
\hline & & Boys & $15.38 \pm 15.00$ & 10.00 & 23.00 & 3.18 & \\
\hline & \multirow{2}{*}{11} & Girls & $12.48 \pm 12.00$ & 4.00 & 25.00 & 4.00 & \multirow{2}{*}{0.001} \\
\hline & & Boys & $14.79 \pm 15.00$ & 8.00 & 23.00 & 3.72 & \\
\hline & \multirow{2}{*}{12} & Girls & $12.56 \pm 13.00$ & 5.00 & 20.00 & 3.73 & \multirow{2}{*}{$<0.001$} \\
\hline & & Boys & $16.49 \pm 16.00$ & 11.00 & 24.00 & 3.33 & \\
\hline
\end{tabular}


Table 5. Angle of thoracic kyphosis with regard to age and sex

\begin{tabular}{|c|c|c|c|c|c|c|c|}
\hline & Age & Sex & Mean $\pm \mathrm{SD}$ & Mediana & Minimum & Maximum & $\mathrm{p}$ \\
\hline \multirow{12}{*}{ Angle of thoracic kyphosis [deg] } & \multirow{2}{*}{7} & Girls & $159.26 \pm 159.15$ & 150.50 & 166.90 & 4.07 & \multirow{2}{*}{0.33} \\
\hline & & Boys & $158.49 \pm 158.20$ & 147.10 & 170.30 & 5.12 & \\
\hline & \multirow{2}{*}{8} & Girls & $159.91 \pm 160.95$ & 145.10 & 170.60 & 5.14 & \multirow{2}{*}{0.13} \\
\hline & & Boys & $158.38 \pm 158.20$ & 151.50 & 169.60 & 4.90 & \\
\hline & \multirow{2}{*}{9} & Girls & $159.70 \pm 159.20$ & 141.40 & 172.40 & 4.74 & \multirow{2}{*}{0.02} \\
\hline & & Boys & $157.64 \pm 157.60$ & 142.10 & 168.20 & 4.89 & \\
\hline & \multirow{2}{*}{10} & Girls & $159.98 \pm 159.00$ & 149.00 & 172.00 & 4.71 & \multirow{2}{*}{$<0.001$} \\
\hline & & Boys & $155.02 \pm 155.00$ & 145.00 & 162.00 & 3.79 & \\
\hline & \multirow{2}{*}{11} & Girls & $158.89 \pm 159.00$ & 146.00 & 170.00 & 5.31 & \multirow{2}{*}{0.10} \\
\hline & & Boys & $157.34 \pm 157.00$ & 145.00 & 165.00 & 4.45 & \\
\hline & \multirow{2}{*}{12} & Girls & $159.08 \pm 159.00$ & 148.00 & 169.00 & 5.33 & \multirow{2}{*}{0.008} \\
\hline & & Boys & $156.15 \pm 156.00$ & 144.00 & 165.00 & 4.39 & \\
\hline
\end{tabular}

Table 6. Angle of lumbar lordosis with regard to age and sex

\begin{tabular}{|c|c|c|c|c|c|c|c|}
\hline & Age & Sex & Mean $\pm \mathrm{SD}$ & Mediana & Minimum & Maximum & $\mathrm{p}$ \\
\hline \multirow{12}{*}{ Angle of lumbar lordosis [deg] } & \multirow{2}{*}{7} & Girls & $160.59 \pm 160.75$ & 150.30 & 169.80 & 5.38 & \multirow{2}{*}{0.31} \\
\hline & & Boys & $162.10 \pm 161.30$ & 144.60 & 175.80 & 5.88 & \\
\hline & \multirow{2}{*}{8} & Girls & $159.49 \pm 159.15$ & 150.60 & 167.10 & 3.97 & \multirow{2}{*}{0.24} \\
\hline & & Boys & $160.84 \pm 161.20$ & 145.80 & 172.70 & 5.92 & \\
\hline & \multirow{2}{*}{9} & Girls & $159.62 \pm 159.80$ & 144.30 & 169.10 & 5.78 & \multirow{2}{*}{0.57} \\
\hline & & Boys & $160.46 \pm 160.60$ & 149.10 & 170.60 & 4.78 & \\
\hline & \multirow{2}{*}{10} & Girls & $156.14 \pm 155.00$ & 150.00 & 168.00 & 4.49 & \multirow{2}{*}{0.73} \\
\hline & & Boys & $155.17 \pm 155.00$ & 135.00 & 166.00 & 6.15 & \\
\hline & \multirow{2}{*}{11} & Girls & $154.55 \pm 155.00$ & 144.00 & 164.00 & 4.86 & \multirow{2}{*}{0.05} \\
\hline & & Boys & $156.14 \pm 156.00$ & 135.00 & 168.00 & 5.53 & \\
\hline & \multirow{2}{*}{12} & Girls & $155.09 \pm 156.00$ & 144.00 & 169.00 & 5.26 & \multirow{2}{*}{0.04} \\
\hline & & Boys & $157.09 \pm 157.00$ & 137.00 & 168.00 & 6.15 & \\
\hline
\end{tabular}

Table 7. Descriptive statistics of the measured parameters in the current study

\begin{tabular}{lcccccc}
\hline \multirow{2}{*}{ Parameter } & \multicolumn{5}{c}{ Descriptive statistics } \\
\cline { 2 - 6 } & $\mathrm{n}$ & Mean \pm SD & Median & Minimum & Maximum & $\mathrm{CV}^{\mathrm{a}}$ \\
\hline$\alpha$ angle [deg] & 562 & $13.29 \pm 5.21$ & 13.45 & -3.1 & 27 & 39.18 \\
$\beta$ angle [deg] & 562 & $8.69 \pm 3.74$ & 8.5 & -3 & 25.1 & 43.06 \\
$\gamma$ angle [deg] & 562 & $12.88 \pm 4.03$ & 12.85 & 2.2 & 25 & 31.3 \\
Angle of thoracic kyphosis [deg] & 562 & $158.32 \pm 4.96$ & 158.05 & 141.4 & 172.4 & 3.13 \\
Angle of lumbar lordosis [deg] & 562 & $157.90 \pm 5.92$ & 158 & 135 & 175.8 & 3.75 \\
\hline
\end{tabular}

\footnotetext{
a Indicates the coefficient of variation.
} 


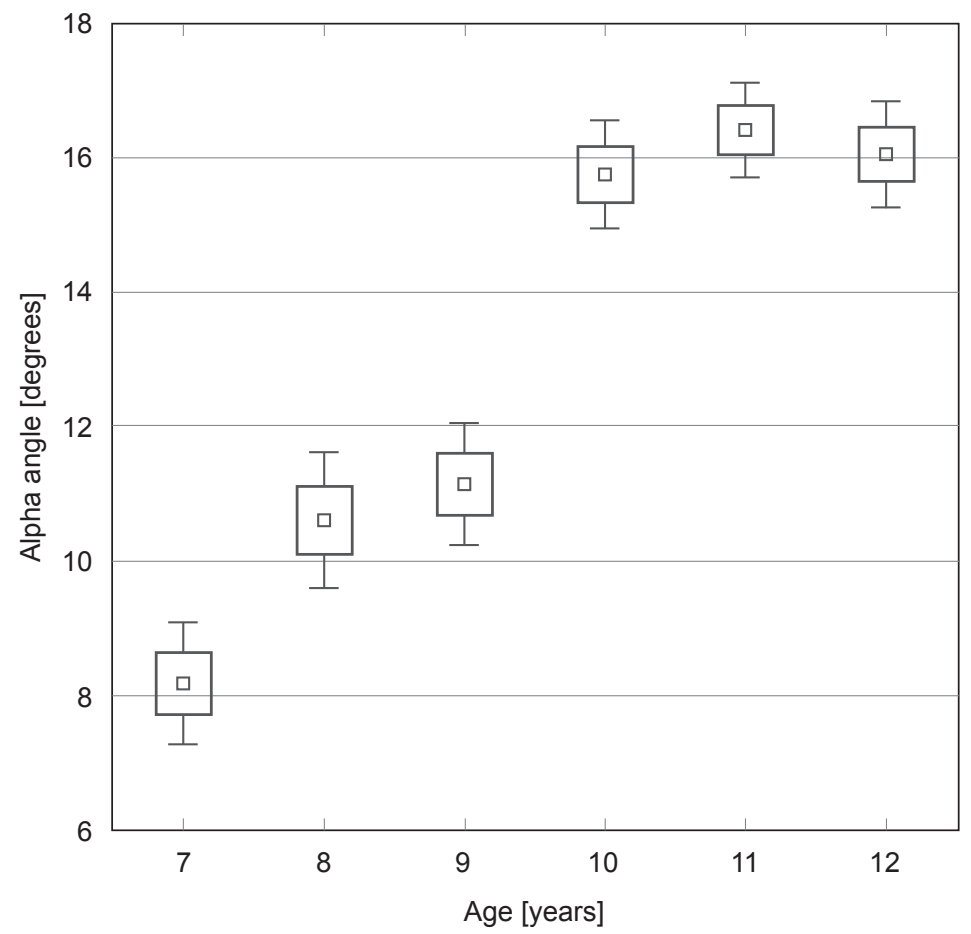

Fig. 2. Alpha angle measurements over time for boys $(n=278)$ and girls $(n=284)$

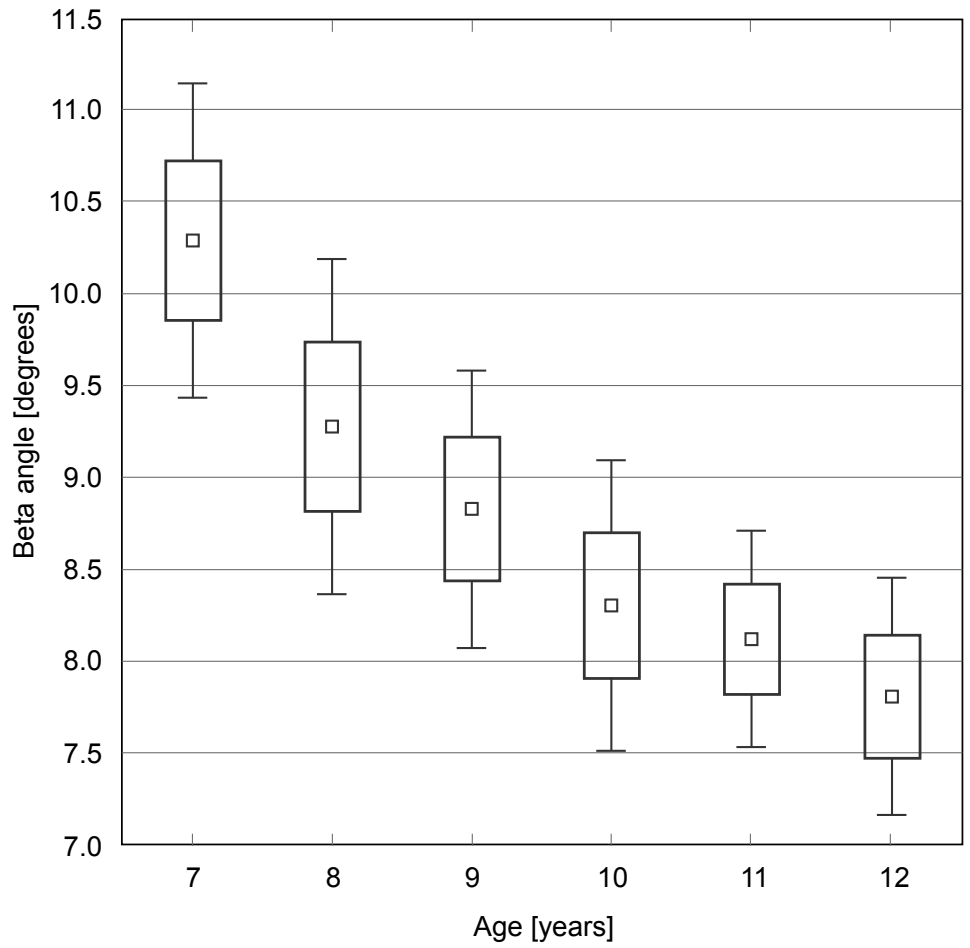

Fig. 3. Beta angle measurements over time for boys $(n=278)$ and girls $(n=284)$

The basic statistics describing the measurements for all of the five parameters are shown in Table 7. For the study population, the Alpha angle increased with an increase in age. The greatest such increase occurred between the $9^{\text {th }}$ and $10^{\text {th }}$ year of life (Fig. 2). Additionally, there was a slight and statistically insignificant drop in the value of the Alpha angle between the $11^{\text {th }}$ and $12^{\text {th }}$ year of life. With regards to the thoracolumbar vertebral segment, this parameter appeared to decrease with age (Fig. 3). However, the differences between the individual 


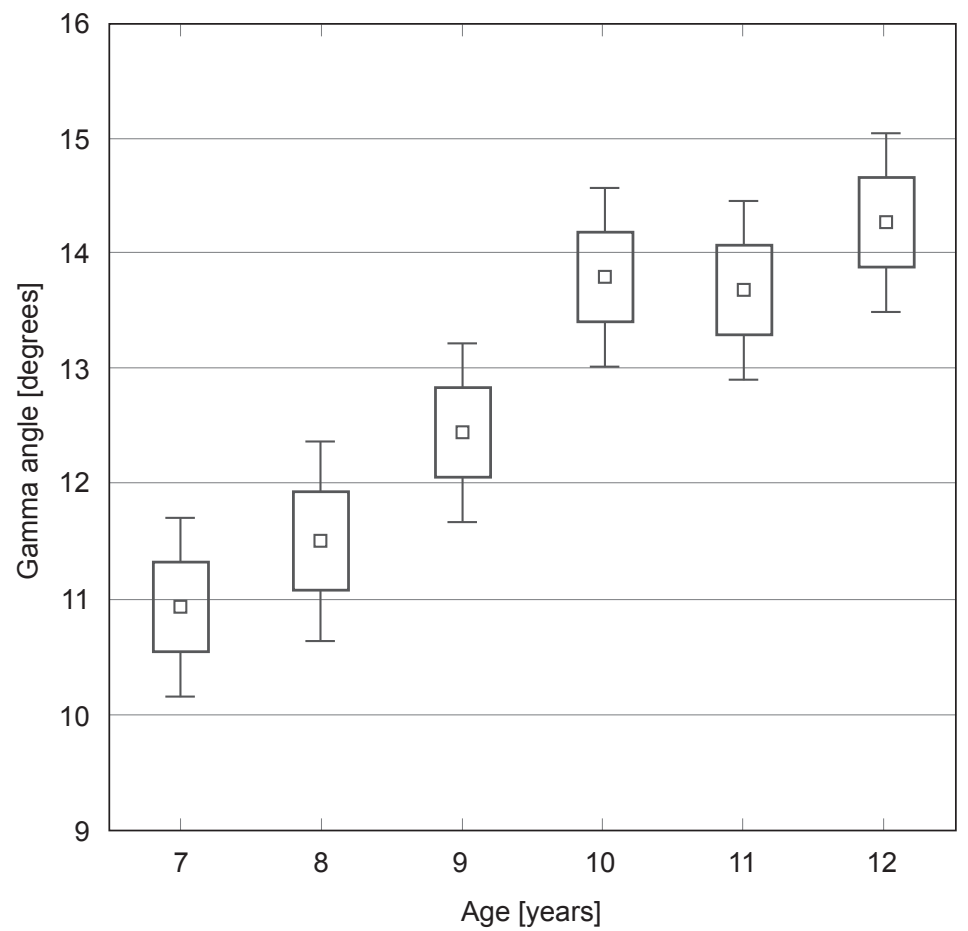

Fig. 4. Gamma angle measurements over time for boys $(n=278)$ and girls $(n=284)$

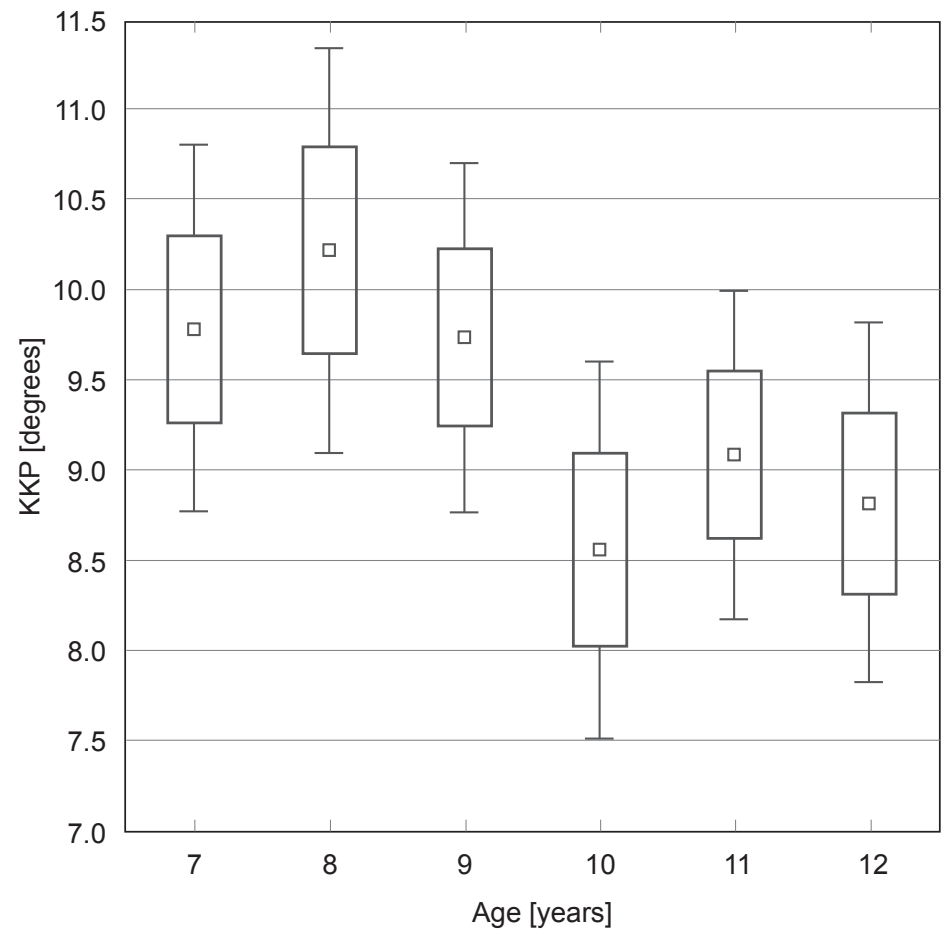

Fig. 5. Angle of thoracic kyphosis measurements over time for boys $(n=278)$ and girls $(n=284)$

age groups were generally not statistically significant. Similar dynamics were observed with the Gamma angle parameter measurements, which appeared to increase with age in the study population, with the exception of an observed reduction occurring between the $10^{\text {th }}$ and $11^{\text {th }}$ years of life (Fig. 4). With regard to the measurements relating to the ATK, the changes in the angle size appeared to be irregular over time (Fig. 5). With regards 


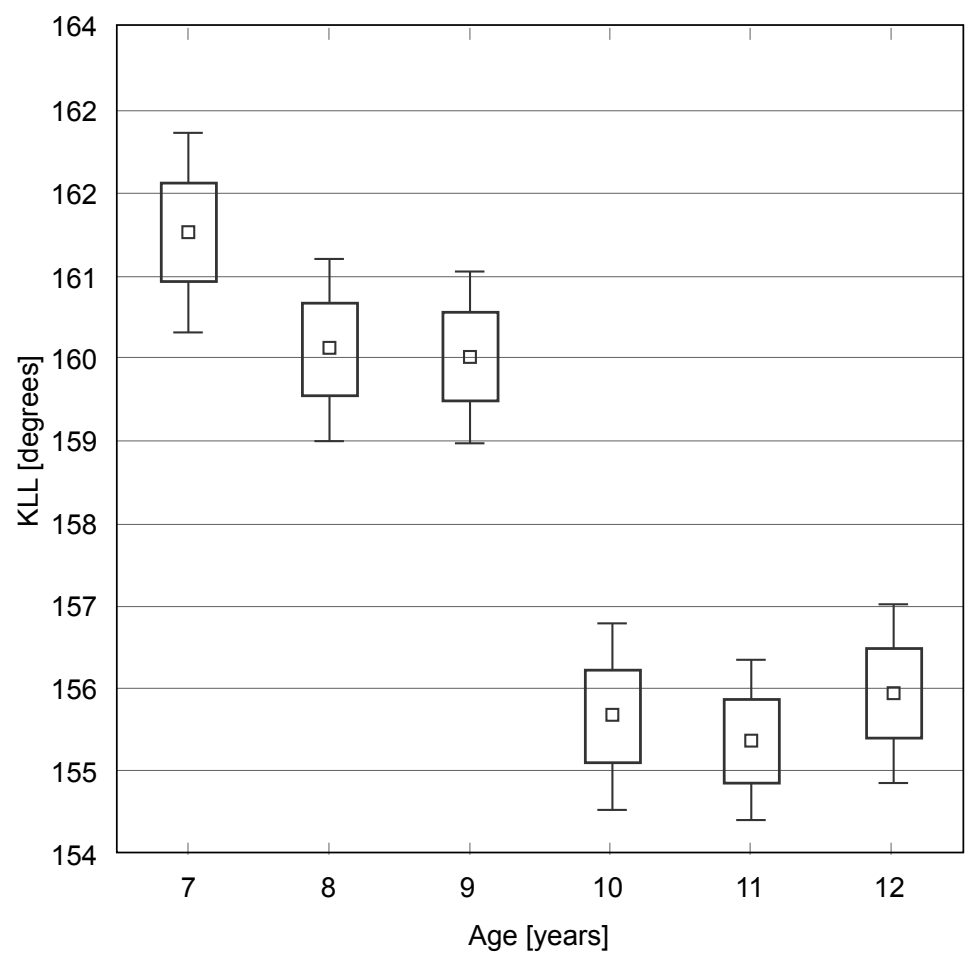

Fig. 6. Angle of lumbar lordosis measurements over time for boys $(n=278)$ and girls $(n=284)$

Table 8. Comparison of the tested parameters between the gender subgroups in the current study

\begin{tabular}{lccc}
\hline Parameter & Boys rank sum & Girls rank sum & $\mathrm{p}$ \\
\hline$\alpha$ angle [deg] & 70576.0 & 87627.0 & $<0.001$ \\
$\beta$ angle [deg] & 80750.5 & 77452.5 & 0.19 \\
$\gamma$ angle [deg] & 88781.5 & 69421.5 & $<0.001$ \\
Angle of thoracic kyphosis [deg] & 67672.5 & 90530.5 & $<0.001$ \\
Angle of lumbar lordosis [deg] & 83706.5 & 74496.5 & 0.004 \\
\hline
\end{tabular}

to the ALL measurements, the size of this parameter appeared to decrease with an increase in age, with the greatest decrease occurring between the $9^{\text {th }}$ and $10^{\text {th }}$ year of life (Fig. 6). Thereafter, the ALL increased between the $11^{\text {th }}$ and $12^{\text {th }}$ year of life.

When analysing the parameters, statistically significant differences were shown between the subgroups of boys and girls for 4 out of the 5 tested parameters (Table 8). The only exception to this was the Beta angle (the inclination of the thoracolumbar vertebral segment), which showed no statistically significant difference between the two gender subgroups. The largest statistically significant difference between the two gender subgroups was observed with respect to the recorded Gamma and ATK angles. This may be because the vertebral column of a female child is characterised by a significantly larger inclination of the lumber segment (Alpha angle) and the angle of thoracic kyphosis, whereas the Gamma angle and the angle of lumbar lordosis are significantly smaller.

\section{Discussion}

Postural development in ontogenesis is a dynamic process. As a result, it can be difficult to assess and provide standard values for what constitutes a "normal" posture or a postural abnormality. In the case of the frontal plane, postural symmetry is evaluated. However, depending on the researcher and the methodology used, it may be arguable what degree of asymmetry in the paired ossification points should be considered as 
significant, borderline or normal. It is even more difficult to determine the normal range of values for the sagittal plane. It is only known that curvatures should have a mild contour and should be relatively balanced. If any normal values have been determined, they have been applied only to a given study population group. Due to these difficulties, assessments are conducted not with regard to the specific angular value of the curvatures in the study group, but rather to the differences in these values between the subgroups which are characterised by sex, age or level of physical activity. This type of information sheds light on what factors posture may be dependent upon, and what issues can significantly affect postural changes.

Age is one of the factors which affect posture. The posture of a child differs significantly from the posture of an adult. Moreover, children at various stages of development also differ in terms of their posture. Postural differences between the sexes are generally less obvious due to the fact that age is often excluded from such an analysis. Such differences are mostly observed in adolescents in the $2^{\text {nd }}$ critical period of posturogenesis [6]. This paper presents an analysis of 5 postural parameters in children aged 7 to 12 years. In addition, the parameters were analysed according to the gender subclassification and the differences were noted.

Lichota studied the inclination of individual vertebral segments with respect to gender and age [13]. More specifically, the author went on to show that the posture of boys was characterised by larger Alpha and Gamma angles, compared to those found in girls; whilst any gender-related differences with respect to the Beta angle was minimal. In a follow-up observation after one year, the authors reported that the inclination of the anteriorposterior spinal curvatures, especially the $\beta$ angle, had increased significantly. These results were confirmed by Xiong et al. [21]. Furthermore, Wilner and Johnson observed an age-related increase in the angle of thoracic kyphosis. However, between 10 and 12 years of age, the ATK tended to decrease [20]. Cil et al. and Giglio and Volpon examined the postural characteristics of a population of children and young people aged between 5 and 20 years. The scientists showed that the angle of lumbar lordosis increased with age $[3,8]$. Willner and Johnson also examined a group of 1101 children aged between 8 and 16 years [20]. These authors observed that the smallest angle of thoracic kyphosis appeared in children aged 10-12 years, and there was a statistically significant increase in the angle of thoracic kyphosis in the 8,14 and 16 year old age groups.

In the current study, the Alpha and Gamma angles increased steadily with age whilst the $\beta$ angle reduced steadily over time. Only a slight reduction in the $\beta$ angle was observed between 10 and 11 years of age. The ATK angle reduced and increased in an alternating fashion, with no clearly discernible pattern of development. However, the observed differences were not statistically significant. Conversely, the ALL angle reduced significantly with age, with the largest decrease observed between the $9^{\text {th }}$ and $10^{\text {th }}$ years of life. According to Lang-Tapia et al., men tend to exhibit smaller lumbar lordosis angles and larger thoracic kyphosis angles when compared to women [11, 12]. This observation is similar to the conclusions reached by Whitcome et al., who explained the size of the lumbar lordosis in women in terms of the large pelvic space required for a foetus during pregnancy [19]. In addition, Cil et al. were unable to show a relationship between the size of the thoracic kyphosis angle and the lumbar lordosis angle with the gender of children and adolescents aged from 5 to 20 years [3].

In this study, the girls tended to have a larger angle of lumbar lordosis and a smaller angle of thoracic kyphosis compared to the boys. This is similar to the results obtained by Poussa et al [18]. They furthermore measured the inclination angles of individual vertebral segments and a larger inclination of the lumbosacral vertebral segment was observed in women compared to men. In contrast, the men tended to have a larger inclination of the lumbothoracic vertebral segment. No gender-specific statistically significant differences were found in the inclination of the upper thoracic vertebral segment.

The results of the current study partially correlated with those obtained by the other authors. In terms of agerelated changes in the inclination of individual vertebral segments, the Alpha and Gamma angles were shown to increase in size. On the other hand, the Beta angle was shown to progressively decrease with age. The size of the angle of the lumbar lordosis also decreased steadily with age. These result were confirmed in the study by MacThiong et al. [14]. In addition, the size of the angle of thoracic kyphosis appeared to show no correlation with the age of the individual.

Non-correlations between the results of the current study and others published in the literature may partially be explained by the fact that the other studies concentrated on different age groups. In addition, it may be difficult to compare our results with those of others, since population groups from different regions of the world were enrolled in each of the different studies. Thus far, no data has been published which has attempted to identify environmental factors, such as the geographical locality, which may significantly affect the size and distribution of the different postural parameters. Some authors have already shown that a decrease in the lumbar lordosis angle size is positively correlated with the age of an individual $[3,8]$. 


\section{Value of the study}

The current study presented the dynamics of the anterior-posterior spinal curvature development. The body posture appears to be highly dependent on both the subject's age and gender.

\section{Limitations of the study}

It may be difficult to extrapolate the current results to the larger global population. It may also prove worthwhile to extend the current research by comparing the postures of children from various regions of the world. Such an undertaking would undoubtedly go some way to shedding light on the factors which influence posture and mapping the naturalistic normal development of different population groups. To the best of our knowledge, this type of investigation has yet to be undertaken, and it may provide useful for clinical insights in the future.

\section{Conclusions}

The study findings can be used for the accurate mapping of normal postural development and, inter alia, for the detection and diagnosis of an emerging abnormal posture. Importantly, a correct postural assessment algorithm for children should include the subject's age and sex.

\section{References}

1. Bankoff A.D.P., Brighetti V. (1986) Levantamento da Incidência de Cifose Postural e Ombros Caídos em Alunos de $1^{\mathrm{a}}$ à $4^{\mathrm{a}}$ séries escolar. Revista Brasileira de Ciências do Esporte, 7(3): 93-97.

2. Betsch M., Wild M., Jungbluth P., et al. (2010) The rasterstereographic-dynamic analysis of posture in adolescents using a modified Matthiass test. Eur. Spine J., 19: 1735-1739. DOI: 10.1007/s00586-010-1450-6. Epub 2010 May 20.

3. Cil A., Yazic M., Uzumcugil A., Kandemir U., Alanay A., Alanay Y., Acaroglu R.E., Surat A. (2005) The evolution of sagittal alignment of the spine during childhood. Spine, 30: 93-100.

4. Drerup B., Ellger B., Meyer zu Bentrup F.M., et al. (2001) Functional rasterstereographic images: a new method for biomechanical analysis of skeletal geometry. Orthopade, 30(4): 242-250.

5. Drerup B., Ellger B., Meyer zu Bentrup F.M., Hierholzer E. (2014) Rasterstereographic measurement of scoliotic deformity. Scoliosis 12; 9(1): 22. DOI: 10.1186/ s13013-014-0022-7

6. Drzał-Grabiec J., Snela S., Rykała J., Podgórska J., Truszczyńska A. (2014) The influence of elongation exer- cises on the anterior-posterior spine curvatures. Biomed. Hum. Kinet., 6(1): 1-4.

7. Drzał-Grabiec J., Truszczyńska A., Rykała J., Rachwał M., Snela S., Podgórska J. (2015) The effect of asymmetrical backpack load on spine in children on the spinal curvatures. Work, 5; 51(2): 383-388. DOI: 10.3233/WOR141981.

8. Giglio C.A., Volpon J.B. (2007) Development and evaluation of thoracic kyphosis and lumbar lordosis during growth. J. Child. Orthop., 1: 187-193. DOI: 10.1007/ s11832-007-0033-5. Epub 2007 Jul 28.

9. Hackenberg L., Liljenqvist U., Hierholzer E., Halm H. (2000) Scanning stereographic surface measurement in idiopathic scoliosis after VDS (ventral derotation spondylodesis). Z. Orthop. Ihre Grenzgeb., 138: 353-359.

10. Iunes D., Cecílio M., Dozza M., Almeida P.R. (2010) Quantitative photogrammetric analysis of the Klapp method for treating idiopathic scoliosis. Rev. Bras. Fisioter., 14: 133-140.

11. Lang-Tapia M., España-Romero V., Anelo J., Castillo M.J. (2011) Differences on spinal curvature in standing position by gender, age and weight status using a noninvasive method. J. Appl. Biomech., 27: 143-150.

12. Lewis J., Valentine R. (2010) Clinical measurement of the thoracic kyphosis. A study of the intra-rater reliability in subjects with and without shoulder pain. BMC Musculoskelet Disord., 11: 39. DOI: 10.1186/1471-2474-11-39.

13. Lichota M. (2008) Changes in the anterior-posterior spinal curvatures in children aged 6-7 years. Phys. Educ. Sport, 52: 17-20.

14. Mac-Thiong J.M., Berthonnaud É., Dimar J.R., Betz R.R., Labelle H. (2004) Sagittal Alignment of the Spine and Pelvis During Growth. Spine, 29(15): 1642-1647.

15. Pazos V., Cheriet F., Song L., Labelle H., Dansereau J. (2008) Accuracy assessment of human trunk surface 3D reconstructions from an optical digitizing system. Med. Biol. Engon. Comp., 43: 11-15.

16. Penha P.J., João S.M., Casarotto R.A., Amino C.J., Penteado D.C. (2005) Postural assessment of girls between 7 and 10 years of age. Clinics (Sao Paulo). 60(1): 9-16.

17. Porto F., Gurgel J.L., Russomano T., Farinatti Pde T. (2010) Moiré topography: characteristics and clinical application. Gait Posture, 32: 422-424. DOI: 10.1016/j. gaitpost.2010.06.017.

18. Poussa M.S., Heliövaara M.M., Seitsamo J.T., Könönen M.H., Hurmerinta K.A., Nissinen M.J. (2005) Development of spinal posture in a cohort of children from the age of 11 to 22 years. Eur Spine J., 14(8): 738-742.

19. Whitcome K., Shapiro L., Lieberman D. (2007) Fetal load and the evolution of lumbar lordosis in bipedal hominins. Nature, 450: 1075-1078. 
20. Willner S., Johnson B. (1983) Thoracic kyphosis and lumbar lordosis during the growth period in children. Acta Paediatr.,72: 873-878.

21. Xiong B., Sevastik J., Hedlund R., Sevastik B. (1998) Sagittal configuration of the spine and growth of the posterior elements in early scoliosis. J. Orthop. Res., 12: 113-118.

22. Zubovic A., Davies N., Berryman F., Pynsent P., Quraishi N., Lavy C., Bowden G., Wilson-Macdonald J.,
Fairbank J. (2008) New method of scoliosis deformity assessment: ISIS 2 SYSTEM. Stud. Health Technol. Inform., 140: 157-160.

\section{Received 02.03.2016 \\ Accepted 16.05.2016}

@ University of Physical Education, Warsaw, Poland 